\title{
LA PENA COMO PENITENCIA SECULAR. APUNTES SOBRE EL SENTIDO DE LA EJECUCIÓN DE LA PENA*
}

\author{
Jonatan Valenzuela Saldias**
}

\begin{abstract}
RESUMEN
El presente trabajo intenta dar cuenta de un grupo de argumentos relevantes para la comprensión del sentido de la ejecución de la pena, desde la tesis esbozada por R.A. Duff. Utiliza las referencias teóricas de una cierta teoría de la pena presente en Duff e intenta proyectar estos argumentos hacia la racionalidad administrativa de la ejecución penal. De esta manera, se intenta conciliar la comprensión de la pena con las razones, generalmente, asociadas a la penitencia. Sobre esta base, se intenta construir un argumento sobre el sentido que deberían tener las reglas de ejecución de la pena.
\end{abstract}

DERECHO PENAL - POLÍTICA CRIMINAL - EJECUCIÓN DE LA PENA

\author{
Legal punishment as a secular penitence. \\ Notes on the meaning of punishment application
}

\begin{abstract}
The present work attempts to show a group of relevant arguments to understand the meaning of punishment application, from the thesis drawn by R.A. Duff. It uses the theoretical references of a certain theory of the punishment present in Duff and attempts to project these arguments towards the administrative rationality of the application of criminal punishment. This way, an attempt is made to conciliate the understanding of the punishment with the reasons that are generally associated with religious penitence. On this basis, it is attempted to build an argument on the meanings that the rules of punishment application should have.
\end{abstract}

\section{CRIMINAL LAW - CRIMINAL POLICY - PUNISHMENT APPLICATION}

* El presente trabajo constituye una versión, espero que mejorada, del texto que fue sometido a discusión los días 16 y 24 de abril de 2009 en las Facultades de Derecho de la Universidad Adolfo Ibáñez (Santiago) y de la Universidad Austral de Chile (Valdivia). Agradezco a los asistentes a estas discusiones las valiosas observaciones planteadas, las que me han permitido modificar parcialmente el contenido del artículo. En particular deseo expresar mi agradecimiento al estudiante de Doctorado en Derecho de la Universidad de Edimburgo (UK) Francisco Saffie, por sus comentarios a una versión preliminar de este trabajo. Estoy en deuda también con un anónimo lector crítico, quien realizara el arbitraje de este trabajo. Agradezco el tiempo y la energía en intentar que este texto mejorara.

** Abogado, Estudiante de Doctorado en Derecho, Universitat de Girona, Facultat de Dret, Campus Montilivi s/n, 17071, Girona (España), jonatan.valenzuela@udg.edu

Artículo recibido el 4 de septiembre de 2009 y aceptado para su publicación por el Comité Editorial el 28 de mayo de 2010. 


\section{INTRODUCCIÓN}

$\mathrm{E}$ 1 sentido de la pena excede con mucho el marco que tradicionalmente se le ha dedicado en la doctrina chilena.

Si bien es cierto que existen pronunciamientos, casi todos se dirigen hacia la ratificación de una especie de consenso tácito en torno al desarrollo, más o menos detallado, de las tesis consecuencialistas. En ese marco, de lo que se ha tratado es de dar contenido a las tesis preventivas, bajo el alero tradicional de una explicación utilitaria para fundamentar la regla de imposición de la pena.

En este trabajo pretendo abordar ciertas cuestiones en torno al sentido que puede tener la pena, en el marco de su ejecución o, si se quiere, desde la perspectiva de la forma que el castigo toma una vez puestos en juego los ideales de censura y proporcionalidad del sistema.

Esta es una cuestión que en la doctrina penal chilena se encuentra relativamente descuidada, debido principalmente, desde mi punto de vista, a un contexto legal escaso y de poca fuerza expresiva. Dicho de otro modo, la regulación chilena sobre ejecución de la pena es en un sentido relevante no democrática (el núcleo principal de normas se encuentra en un nivel infralegal con la consiguiente insatisfacción del principio de legalidad) y esto parece restarle relevancia a la discusión académica en la materia.

Esta propiedad, en un sistema continental como el nuestro, parece ofrecer grandes dificultades para construir una teoría sobre la forma de la pena en la etapa de ejecución.

Este rasgo complejo, creo que se expresa en dos sentidos fundamentales. Por una parte, la regulación acerca de la ejecución de la pena en Chile no tiene rango legal. He sostenido en un trabajo relativamente antiguo que esta propiedad pone a la ejecución de la pena en situación de incumplir el principio de legalidad en sentido amplio ${ }^{1}$. Hoy creo que este no es el enfoque decisivo. La cuestión está en reconocer la irrelevancia democrática que tienen las cuestiones sobre sentido del plan de ejecución de la pena, bajo una tesis exigente de la democracia.

Una tesis democrática -en conexión con el derecho penal por cierto- implicaría notar como una cuestión extraña que el destino de la pena luego de la imposición judicial sea democráticamente irrelevante, al no encontrarse dentro del espacio reservado para la ley dentro de la comunidad.

Por otra parte, existe el acusado defecto en torno a la pérdida de derechos civiles de parte de ciertos condenados en el sistema. La pérdida de ciudadanía refuerza este carácter irrelevante de las discusiones sobre la pena y su ejecución, al encontrarnos en un espacio de disolución de la participación democrática del condenado.

En este trabajo no pretendo solucionar estas cuestiones. De hecho, no es mi objetivo analizar cómo una determinada teoría exigente de la democracia puede dar lugar a un discurso reivindicativo en el marco político para evitar esta situación. Lo que quiero es intentar sentar

${ }^{1}$ Véase Valenzuela, J., "El estado actual a la reforma del sistema penitenciario en Chile”, en Revista de Estudios de la Justicia, núm. 6, 2005, pp. 191-209. 
una base para discutir ciertos supuestos teóricos sobre la ejecución de la pena, partiendo de la base de que el defecto estructural en el que parece apoyarse gran parte de la doctrina nacional para dedicar poco espacio a estos problemas no es excusa suficiente.

Dicho esto, lo que pretendo en este trabajo es, como he advertido, sentar ciertas bases teóricas, que provienen principalmente del ámbito anglosajón sobre justificación de la pena. No pretendo cerrar absolutamente las cuestiones que se plantean aquí, pues el ideal es generar una agenda académica en torno a estas cuestiones que deba ser desarrollada en el futuro.

La tesis defendida en este trabajo es que, bajo cierta comprensión de la pena, existen argumentos para dar sentido a la etapa de ejecución. En particular con miras a la reconciliación entre el penado y la comunidad. La base de este argumento está desarrollada bajo un prisma retributivo de justificación de la regla de imposición de la pena.

\section{El contexto del problema}

R.A. Duff plantea una pregunta sobre los términos en que puede abordarse la legitimidad en el Derecho Penal. La pregunta es cuál es el papel legítimo que cabe atribuir, en el contexto del Derecho Penal y su mecanismo de castigo, a las razones de orden religioso o asociadas a valores vinculados a la religión ${ }^{2}$.

Es evidente para cualquier lector de Derecho Penal que la pregunta sobre la concurrencia de razones morales, más vinculadas a la idea de religión, ha sido respondida con extrema dureza por parte de una arraigada tradición de filosofía penal que intenta reconocer en la puesta en juego de razones morales una mayor o menor intromisión en la órbita privada de los integrantes de la comunidad. Esta intromisión ha sido frecuentemente valorada como una cuestión indeseable por la constante "defensa" que deben realizar los ciudadanos del ejercicio del plan punitivo estatal.

La razón fundamental para esta respuesta está constituida por considerar que no es legítimo que el Estado, por medio de acciones de autoridad, inculque una determinada creencia $^{3}$. Las claves de autonomía y privacidad constituyen una "actitud liberal" ante el problema de las razones religiosas frente al Derecho Penal. En términos de Duff, las razones morales se asocian al alma de los ciudadanos, y el alma de los ciudadanos es algo que no interesa al Estado en el ejercicio de la práctica punitiva.

La actitud liberal frente al problema debe renegar del juego de los valores morales o religiosos, en el nivel de la legitimidad del sistema. Además, debe afirmar la neutralidad ante concepciones, morales o religiosas, acerca del bien ${ }^{4}$.

${ }^{2}$ Véase Duff, R. A. "Penance, punishment and the limits of community", en Punishment and Society, núm. 5, 2003, p. 295.

${ }^{3}$ Ibidem, p. 296.

${ }^{4}$ Paradigmáticamente en este sentido puede verse Roxin, C., Derecho Penal Parte General. Fundamentos. La estructura de la teoría del delito. Madrid: Civitas, pp. 52-64. 
Existen dos aspectos en que la tradición liberal cuenta con ventajas importantes. Por una parte, reconoce la necesidad de que un determinado resultado acaezca en el mundo para poder predicar la pertinencia de una intervención punitiva. Es necesario reconocer una determina ofensa a otros de parte del autor del delito. Por otra parte, resulta necesario conectar el hecho que acaece en forma de resultado en el mundo con un determinado agente. En términos genéricos, debe tratarse de un hecho que tenga un culpable. De esta manera, la responsabilidad penal puede ser explicada en términos de elección y control. Uno es responsable penalmente por aquello que elige hacer ${ }^{5}$.

Sacerdotes y moralistas se encontrarían firmemente interesados en las dimensiones más profundas acerca de los motivos para tomar esa decisión. Serían, en este contexto, relevantes el carácter del alma del infractor, los sentimientos asociados a su conducta y la "mentira" que estaría detrás de la conducta externa y que constituiría la esencia del pecado o el acto vicioso. El Derecho Penal, en cambio, manifiesta un interés limitado a la conducta y a las condiciones específicas de la responsabilidad por la conducta.

Esta ha sido la actitud dominante en el Derecho Penal por largo tiempo. Sin embargo, hoy es posible reconocer un esfuerzo por reconectar al Derecho Penal con las razones emotivas que rodean a la conducta ${ }^{6}$.

En este sentido se inscribe la versión de un Derecho Penal que pretende servir de herramienta de educación moral $^{7}$.

La pena puede tener una función preventiva de comisión de delitos en el futuro. Sin embargo, esta función preventiva puede ser descrita como un hecho que da cuenta de la utilidad de la herramienta penal y no como un fundamento.

Esta es una cuestión crucial en el planteamiento de Hampton pues considera, por otra parte, que la justificación utilitaria neutra, es decir, una justificación utilitaria que prescinda de la correlación entre la carga moral de no cometer delitos y el merecimiento de sanción por el hecho de cometerlos, pone a la punición en situación de generar un trato degradante con los integrantes de la comunidad.

De acuerdo a una teoría educativa del Derecho Penal, la imposición de la pena puede sostener sobre sí la carga de enseñar al autor del delito que lo hecho se encuentra mal. Pero esta no es una razón para fundamentar la punición, se es acreedor de la pena en virtud de un argumento retributivo. Lo que sí es que el hecho de padecer la pena puede servir de medio para expresar, en términos morales, lo que se encuentra bien.

El mensaje moral implícito en el acto de imposición de la pena es lo que expresa educación. Se educa, en el contexto del Derecho Penal, cuando se contrasta la evidencia

${ }^{5}$ Véase Duff, R. A., "Penance...”, op. cit., p. 296.

${ }^{6}$ La relación entre emociones y derecho cuenta con una amplia literatura, al respecto véase, Kulemkampff, A., "Ética nomológica y moral de los sentimientos. Observaciones sobre un problema descuidado por la filosofía práctica", en Doxa, núm. 6, 1989, pp. 405-425; Turner, J., “Justice and Emotions”, en Soc Just Res, núm. 20, 2007, pp. 288-311.

7 Véase Hampton, J., "The moral education theory of punishment”, en Simmons, A.; Cohen, M.; Cohen, J.; Beitz, C., "Punishment”, Princeton: Princeton University Press, 1995, pp. 112-142. 
moral de lo correcto (jurídicamente señalado) con la acción defectuosa del autor. El autor, entiende o aprende de la pena, que moralmente se encuentra en un error.

Este aprendizaje, moralmente marcado, debe entregar razones al ofensor para elegir realizar una conducta que no se encuentre proscrita.

Para esta tesis, la relación entre reprobación y educación está definida por la necesidad de reconocer dos ámbitos de juego en la justificación del castigo. Por una parte, la justificación general del castigo no puede considerar la variable utilitaria, es decir, no se puede fundamentar la práctica punitiva general de una sociedad en la educación. La pena es un mal diseñado en general, y debe constituir un sufrimiento para ser reconocida como pena.

Por otra parte, el acto particular de imposición de la pena sí puede admitir el ingreso de la variable educación. Así, una teoría educativa de la pena -en palabras de Hampton- es una manera de ayudar al autor a ganar el conocimiento moral, si quiere ganarlo.

Esto diferencia a una teoría educativa del Derecho Penal de las versiones rehabilitadoras o de tratamiento. Una tesis educativa reniega de la justificación utilitaria, admitiendo la operación de una variable "preventiva" al interior del juicio de reproche. Así, no se trata de enfrentar al autor del delito como una persona enferma, sino de generar un espacio para entregar un mensaje con carga moral al autor de un delito ${ }^{8}$.

Esta versión de justificación del Derecho Penal constituye la tendencia de la que Duff desea obtener réditos. Un Derecho Penal basado en la idea de educación moral, y su obvia conexión con el nivel de la práctica religiosa, constituye una forma de entender al sistema en conjunto. No como el sistema funciona o existe en este instante pero sí como debería ser comprendido. Junto a ello, una visión como la tomada por Duff permite manejar un grupo de herramientas críticas respecto del actual funcionamiento del Derecho Penal ${ }^{9}$.

Para efectos de la comprensión de la ejecución de la pena, en nuestro sistema, es posible, de la mano de los argumentos presentados, justificar las acciones tendientes a la "resocialización" de los penados. Estos argumentos tienen la ventaja de negar como punto de partida la capitis deminutio que se afirma desde las tradicionales corrientes utilitaristas y, por otra parte, ponen al penado en situación de ser considerado un agente con planes morales relevantes, que pueden ser atendidos al momento de ejecución de la pena. Ahora, estos argumentos -que si bien permiten delimitar las cuestiones sobre la fundamentación del castigo, de las cuestiones sobre la relevancia de la agencia moral del castigado- no resultan totalmente concluyentes si no les asociamos otro nivel de sentido determinado, en este caso por la idea de penitencia.

${ }^{8}$ Una tesis como la defendida por Hampton tiene relevancia para el análisis particular de lo que se ha denominado la "pena juvenil”. Al respecto, véase Valenzuela, J., "La pena y la educación. Una aproximación al fundamento de la pena juvenil”, en Revista de Estudios de la Justicia, núm. 11, 2009, pp. 235-261.

9 Duff, R. A., "Penance...", op. cit., p. 299. 


\section{Penitencia, Religiosa y SECUlar}

Para enfrentar, en abstracto, la posibilidad de imposición de una pena, el punto de partida es un juicio hipotético: un miembro de la comunidad ha pecado. Este pecado expresa una lesión de intereses de otros miembros de la comunidad, pero más expresivamente contiene un fallo en la motivación interna del pecador.

Una cuestión interesante está en valorar que el pecado consiste precisamente en el fallo de los motivos para realizar la acción. Estos fallos pueden contraponerse a la decisión de confesar la falta.

La confesión se encuentra intensamente relacionada con la disculpa o el perdón. La confesión, en algún sentido, constituye al perdón. La confesión y el arrepentimiento expresan la necesidad del perdón por el pecado cometido. Por medio de la confesión, el arrepentimiento y el perdón se reconstituye la relación entre el pecador y su comunidad. Se compensa el daño que ha causado el hecho de la falta ${ }^{10}$.

Sin embargo, la confesión y el perdón no terminan con el problema. El círculo se cierra por medio de la penitencia. La penitencia constituye un mecanismo necesariamente doloroso o desagradable para el pecador en conexión con el mal de su pecado.

La penitencia expresa la comprensión del mal causado. Es una cuestión que interesa a los restantes miembros de la comunidad y al pecador. No es una cuestión relevante para obtener el perdón de Dios. Dios no necesita evidencia de la seriedad del arrepentimiento y del padecimiento por la falta cometida. Quien lo necesita es el pecador. La penitencia es una forma de tomarse en serio el hecho del arrepentimiento y la obtención del perdón ${ }^{11}$.

Por otra parte, la penitencia es prescrita por medio de un mecanismo formal y aprehensible por los demás miembros de la comunidad. En esta medida, tiene un sentido simbólico para ellos.

La penitencia es un medio para recomponer la relación entre el pecador y los demás miembros de la comunidad. En este sentido es un mecanismo inclusivo para el pecador.

Para acceder al nivel de comunicación simbólica imbricado con la penitencia es necesario ser reconocido como un miembro de la comunidad. Sólo los miembros de la comunidad que tengan una relación establecida con los otros pueden recomponer esa relación quebrada por el pecado ${ }^{12}$. Por ello, la excomunión definitiva no es un tipo de penitencia para el que la padece, es tan sólo un medio de separación de la comunidad (no así una excomunión temporal que puede ser tenida como penitencia en la medida que su revocación puede dar lugar a la recomposición de la pertenencia del excomulgado con la comunidad).

Duff defiende la posibilidad de comprender al Derecho Penal como una clase de penitencia secular ${ }^{13}$.

\footnotetext{
${ }^{10}$ Duff, R. A., "Penance...", op. cit., p. 300.

${ }^{11}$ Ibidem.

12 Ibidem, p. 301.

${ }^{13}$ Véase, en general, Duff, R. A., "Penance...", op. cit., 301, y además Duff, R. A., Punishment, communication, and community. New York: Oxford University Press, 2000; Duff, R. A., Answering for crime. Responsibility and Liability in the Criminal Law, Oxford and Portland: Hart Publishing, 2007.
} 
El delito expresa la violación de ciertos valores fundamentales de la comunidad política. Estos se expresan en la ley. La relación producida por la comisión del delito comprende al autor y a la víctima, pero, por cierto, es una cuestión que importa al resto de los miembros de la comunidad.

El penado, en nuestro contexto, puede servirse del sentido de la penitencia para enfrentar y exigir del Estado un "rito" lógicamente similar. No está en juego el merecimiento ni la ofensa contenida en el delito, sino la dignidad del penado en tanto sujeto que puede acceder a este mecanismo de recomposición de la relación entre individuo y comunidad.

Para apreciar cómo el Derecho Penal puede ser comprendido como una clase de penitencia, podemos observar el funcionamiento de las penas alternativas a la privación de libertad. Por ejemplo, el trabajo en beneficio de la comunidad ${ }^{14}$.

El punto central para comprender el trabajo en beneficio de la comunidad no es entender que se realiza un trabajo material para reparar un daño, también material. La cuestión está en entender que se realiza una reparación moral, por una conducta moralmente errónea ${ }^{15}$. Y esta reparación moral busca como correlato, mostrar la seriedad de la ofensa provocada por el delito de la misma manera que la penitencia cristiana.

La pena, en esta perspectiva, puede ser vista como un proceso comunicativo entre el autor y la comunidad política. Por él se comunica al ofensor la censura que merece por la comisión del delito. Se busca traerlo hacia el reconocimiento y arrepentimiento del crimen como un error por el que tiene el deber de realizar una reparación en términos morales.

La pena puede ser una empresa "re-formativa": el ofensor que ha sido llevado al arrepentimiento de su infracción y, con ello, a reconocer la reforma de su conducta futura. La pena debe, en la medida que sea apropiada, asistirlo en ese proceso ${ }^{16}$.

Por cierto, el carácter de "apropiada" de la pena se asocia a la forma que esta toma. La forma punitiva, dominada por la expresión de censura, se integra además con la satisfacción de juicios de adecuación, como la proporcionalidad (en concreto, un juicio de proporcionalidad ordinal) ${ }^{17}$.

La penitencia está dirigida, bajo el esquema propuesto por Duff, no sólo a la conducta del ofensor, sino también a su actitud moral, a sus razones y sentimientos. ${ }^{18}$ Por ello, la pena entendida como penitencia, así como la propia penitencia, están dirigidas a vulnerar el círculo de razones morales íntimas del autor de un delito.

${ }^{14}$ Duff elude expresamente el uso de la prisión como ejemplo, señalando que constituye un caso dramático de violencia y exclusión para el penado, Duff, R. A., "Penance...", op. cit., p. 301.

${ }^{15}$ Duff, R. A., "Penance...", op. cit., 301.

${ }^{16}$ Ibidem.

${ }^{17}$ Esta satisfacción ha sido abordada por Von Hirsch. La pena será adecuada en la medida que sea proporcionada, es decir, que respete la relación entre gravedad del hecho y gravedad de la pena. El juicio que se construye con base en la igualdad (dos casos similares deben recibir un trato sustancialmente similar) es lo central en la denominada proporcionalidad ordinal. Véase Von Hirsch, A., "Censurar y castigar", Barcelona: Trotta, 1998.

${ }^{18}$ Duff, R. A., "Penance...”, op. cit., p. 301. 
La pregunta a la que se enfrenta el planteamiento de Duff en este punto resulta casi obvia. ¿Bajo qué supuesto de legitimidad puede permitirse la pena ingresar en el sector de las convicciones morales del sujeto?

La respuesta depende de la consideración de comunidad en la propuesta de Duff. Para Duff la comunidad constituye al sujeto, de manera que la pertenencia a la comunidad política impone ciertas cargas en la comprensión moral de los sujetos. Los sujetos que pertenecen a una determinada comunidad pueden ser reconocidos como sujetos iguales, en el caso de la pena, debido a que han manifestado pertenencia a ella.

Así es como Murphy ${ }^{19}$ ha comprendido el sentido del amor al prójimo como base para comprender la existencia de una comunidad cristiana. Esta comprensión sirve de cimiento para levantar, en el contexto del discurso de Duff, la posibilidad de concebir a la pena como una cuestión propia de la comunidad, que permita por tanto ser predicada como obra del sujeto que la padece ${ }^{20}$.

Para una tesis que comprenda al Derecho Penal desde la perspectiva sugerida hasta aquí por Duff, las normas penales deben ser consideradas como normas que constituyen a los sujetos que se encuentran llamados a acatarlas. Y en particular, las normas sobre ejecución de la pena deben ser normas dominadas por la razón de reconocimiento del carácter de integrante de la comunidad de quien padece la pena.

El uso del Derecho Penal como penitencia por el Estado puede traer ciertas consecuencias de importancia: primero, diluye los esfuerzos contractualistas que intentan representar a la comunidad política como (cuasi) voluntaria. La obligación comunitaria es habitualmente no voluntaria, los ciudadanos no pueden separarse o considerarse separados de la comunidad ante cada disgusto que puedan manifestar ${ }^{21}$.

Segundo, incluso si podemos reclamar que todos deben aceptar los valores por los que su conducta podrá ser juzgada, no es claro que todo se haga pensando en el juicio a posteriori de la conducta. Es decir, si bien es claro que las reglas que constituyen al derecho de una determinada comunidad (y con ello a la propia comunidad) pueden ser exigidas en términos coactivos, ese rasgo, la exigencia por la fuerza y la consecuente actuación estratégica del destinatario de las reglas, no ofrece una descripción suficientemente fiel ${ }^{22}$.

Tercero, la pena no es, ni debe ser, condicionada a una confesión voluntaria. La confesión y el estatuto privilegiado de no autoincriminación no pueden ser horadados. Sin embargo, el uso del Derecho Penal en torno a la idea de confesión puede ser realizado en la medida que no se realice por medio de un constreñimiento estatal a la misma ${ }^{23}$.

${ }^{19}$ Murphy, J., "Christianity and Criminal Punishment, en Punishment and Society, núm. 5, p. 263.

${ }^{20}$ Con matices, esta idea se encuentra detrás de varias clases de retribucionismo. Véase, entre otros, Mañalich, J. P., "La pena como retribución”, en Revista de Estudios Públicos, núm. 108, 2007, pp. 117-205; Valenzuela, J., "La pena y...”, op. cit.; Moore, M., Placing Blame. A General Theory of Criminal Law, Oxford: Clarendon Press, 1998; Tunick, M., Punishment: Theory and Practice. Berkeley: University of California Press, 1992.

\footnotetext{
${ }^{21}$ Duff, R. A., "Penance...", op. cit., p. 302.

22 Ibidem, p. 302.

${ }^{23}$ Ibidem, p. 302.
} 
Cuarto, la pena no es ni debe ser opcional. La pena expresa un imperativo de justicia que no puede ser enfrentado como un asunto "consecuencial" o neutro para el penado ${ }^{24}$.

Existe una objeción de peso que puede ser realizada desde la perspectiva liberal. El Derecho Penal debe tratar a los ciudadanos como agentes morales relevantes. Ese trato, de agente moral, parece ser traspasado cuando el Estado se permite influir de manera importante en el ánimo moral del sujeto. El Derecho Penal es un ejercicio de poder coercitivo del Estado, que no tiene una entrada legítima en el ámbito de la privacidad de la conciencia de los sujetos.

Duff ensaya una respuesta a esta crítica dividida en tres partes.

Primero, la pena como penitencia secular está dirigida precisamente al autor como agente moral. Muestra la relación que existe entre las actitudes morales y sentimientos y su conducta. No busca, o no debe buscar, que esa faz moral sea corregida. La imposición de la pena es un ejercicio de comunicación moral, en el cual se espera persuadir y llevar a reconocer el hecho defectuoso ${ }^{25}$.

Segundo, el Derecho Penal no necesita, ni debe necesitar, un plan tan ambicioso como el plan religioso. La profundidad de la influencia de la pena y la penitencia no son similares. El delito es un asunto público, en el que se envuelven los rasgos morales que pueden conducir al penado al perdón y arrepentimiento, pero no en el mismo sentido que la penitencia religiosa. El crimen no puede, por cierto, ser analizado en términos de pura conducta externa, pero tampoco en términos de alcanzar el nivel que la penitencia religiosa puede $_{\text {alcanzar }}^{26}$.

Tercero, un Estado que quiera mostrar a sus ciudadanos el respeto debido, como responsables morales, debe dirigirse en una clase determinada de lenguaje moral (no en términos neutros o estratégicos) ${ }^{27}$.

La pena como ha sido representada hasta aquí implica reconocer el carácter de agente moral del infractor y propender a su reconciliación con la comunidad por los valores transgredidos con el delito.

Existen algunas instituciones de la práctica en los sistemas penales actuales donde pueden apreciarse estas características (por ejemplo la probation en los sistemas anglosajones o la suspensión de la pena en el sistema español).

En todo caso, es importante explorar la relación entre una propuesta de justificación normativa y la práctica del sistema penal. Esta puede ser apreciada en tres puntos.

Primero, debe considerarse la creciente utilización de la sensación de la comunidad para presidir las razones de uso del Derecho Penal. Cada vez más, una respuesta moralmente neutra es abandonada por los operadores políticos, poniendo en primer plano la expectativa de comportamiento del sistema de parte de la comunidad ${ }^{28}$.

\footnotetext{
${ }^{24}$ Ibidem, p. 302.

${ }^{25}$ Ibidem, p. 302.

${ }^{26}$ Ibidem, p. 303.

27 Ibidem, p. 303.

${ }^{28}$ Ibidem, p. 304.
} 
Segundo, una tesis como la esbozada por Duff permite concentrar los esfuerzos en perfeccionar los términos en los que el Derecho Penal debe ser "preconcebido". Existen circunstancias que deben ser consideradas como precondiciones para justificar el uso del Derecho Penal. Para ello la proposición de legalidad o ilegalidad de una conducta debe estar recubierta de la seguridad y convicción que constituye a la comunidad política. En otros términos, la decisión de introducir un delito en el catálogo de un determinado Código Penal debe ser correlativa a la manera en que la comunidad se autocomprenda, de forma de poder ser atribuida a la comunidad como autora de sus reglas.

Tercero, la pena, como ha sido representada hasta aquí, implica saltar el camino sencillo de concebir un sistema que sea puramente preventivo o represivo e involucre la posibilidad de considerar a los destinatarios de la norma como responsables morales.

\section{3. ¿LÍMites DE LA COMUNIDAD?}

La pena es, esencialmente, una actividad inclusiva.

Este carácter inclusivo se enfrenta a problemas con ciertas clases de crímenes que parecen aconsejar el uso de una herramienta exclusionaria (pensemos en delitos que provoquen una honda defraudación en las expectativas de la comunidad, por ejemplo, un grave atentado terrorista que cobra miles de víctimas inocentes).

El ejemplo por definición de una pena que impide el ejercicio inclusivo que se ha descrito hasta aquí es la pena de muerte. Otras prácticas como la regulación del three strikes and you re out o el más cercano discurso del Derecho Penal del Enemigo se acercan mecánicamente a esta idea.

En principio, esta clase de prácticas deben ser rechazadas desde una pena concebida como penitencia secular. La cuestión es que puede verificarse que cada vez más clases de delitos y autores son acercados a los mecanismos de exclusión penal.

La cuestión está en abordar los límites de la comunidad. Como se ha descrito, la comunidad determina la comprensión del sujeto que puede ser sometido como un responsable moral a la pena-penitencia. ¿Existen casos en que la comunidad deba reconocer sus límites y considerar que respecto de un caso en concreto debe renunciarse a esa configuración?

Tres clases de ejemplos pueden aclarar esta cuestión. Primero, crímenes de horrible crueldad e inhumanidad que parecen hacer imposible la restauración entre el autor y la comunidad. Segundo, carreras criminales, reincidencia constante de parte de un infractor en delitos violentos, que muestren una tendencia incorregible a abusar de los valores de la comunidad. Tercero, ataques terroristas como los acaecidos en Estados Unidos en septiembre de 2001.

La respuesta al primero de los ejemplos debe ser negativa. No debe separarse al sujeto que comete el crimen horrible y cruel de la comunidad. Si el autor es un responsable moral, entonces esta condición debe presidir su trato frente al Derecho Penal. La crueldad y antipatía que genera la realización de un determinado crimen parece no constituir una razón suficiente para excluir la posibilidad de recomposición de la relación entre el sujeto y la comunidad. Por ello, las reglas de ejecución deben seguir la forma que hemos propuesto en este trabajo dando espacio a la reconciliación. 
La respuesta respecto del segundo caso debe ser, también, negativa. Sin embargo, esta negativa depende de considerar el estatuto de responsable moral y de pertenencia a la comunidad como una cuestión absoluta e irrevocable. Si se reconoce en un momento al reincidente como un agente responsable de la comunidad resulta compleja la operación de trasladarlo hacia un sector donde sus propiedades de responsable moral sean ignoradas. Además, desde la perspectiva de la ejecución de la pena, el hecho de la reincidencia puede ser enfrentado como un fallo en las condiciones de operación de los argumentos aquí presentados. Un sujeto que es, en realidad, marginado de la comunidad por el sistema penitenciario, difícilmente puede soportar la posibilidad de reconciliarse con la comunidad responsable de su separación.

La tercera cuestión, el terrorismo, se relaciona con la guerra y la pena. Es difícil establecer un límite entre fenómenos distintos de terrorismo (local e internacional por ejemplo, es decir, terrorismo cometido por quienes en principio pertenecen a la comunidad política o por extranjeros), asumiendo que la fenomenología de esta clase de crímenes resulta relevante para la comunidad donde tienen lugar.

La cuestión general estará en reconocer un vínculo entre el ofensor y la comunidad. En la medida que este vínculo no sea reconocible parece difícil pretender la aplicación del aparato teórico presentado. Por ello, quizá el problema tenga que plantearse en un contexto que exceda el de la aplicación cotidiana del Derecho Penal y pase a integrar un terreno diferente donde la expresión de reconciliación tenga en consideración al enemigo en el marco de la guerra y de las reglas de ejecución correctas de la misma.

Es posible que la comunidad se conciba en un contexto donde el Derecho y el castigo sean comprendidos de manera tal de generar un apartado teórico especial para el trato de esta clase de crímenes.

Una alternativa, entonces, estará en determinar que nos encontramos en realidad sobre un terreno en el que el Derecho debe permitir la asunción de un espacio de guerra defensiva respecto del enemigo terrorista. Por cierto, que las razones morales que se encontrarán detrás de esta asunción tienen poco que ver con las que encontraríamos en la aplicación "cotidiana” de la pena. Como ejemplo, no se buscará, en principio, la reconciliación con el enemigo, sino la victoria.

Este es un escenario complejo. Parece necesario contar además con la percepción del ofensor. Si el ofensor se ve a sí mismo como un enemigo del Estado, entonces esta justificación parece ser admisible. Sin embargo, en la medida que la percepción del delito sea más parecida a la práctica del Derecho Penal general, nos encontramos ante un uso exclusionario del Derecho Penal, en principio ilegítimo. Por tanto, es complejo asumir el funcionamiento del sentido de las reglas de ejecución de la pena en el ámbito de los condenados por delitos terroristas. Por cierto, no puede predicarse el sentido reconciliatorio de estas reglas respecto de alguien a quien no se ha opuesto el derecho como razón de la penitencia, sino la guerra ${ }^{29}$.

${ }^{29}$ Sobre Duff y el problema del terrorismo, véase Duff, R. A., "Notes on Punishment and Terrorism", en American Behavioral Scientist, núm. 48, 2005, pp. 758-763. 


\section{Reconstruir el SENTIDo de LA EjeCuCión DE LA PENA EN EL SISTEMA CHILENO}

Si consideramos los argumentos hasta aquí planteados, tenemos que reducir el sentido de las reglas de ejecución de la pena de la siguiente manera:

(1) El penado es un agente moral digno, miembro de la comunidad;

(2) La pena expresa censura (tiene un fundamento retributivo), pero esto no importa poner en duda la deseable posibilidad del perdón y la reconciliación;

(3) La pena es un espacio que puede ser comprendido, con matices, como Duff comprende a la penitencia, puede ser comprendido como una clase de penitencia secular, y que comporta, por tanto, una determinada dignidad.

Este argumento permite decir que las reglas que determinen el destino de los penados en el sistema chileno deben tener por sentido posibilitar el aprendizaje o la opción moral de los penados de alejarse de una carrera criminal.

De esta manera podemos evaluar la práctica del sistema una vez que estas normas se encuentren en el sistema. Podemos decir, por ejemplo, que una regla como la de pérdida de los derechos ciudadanos por parte del condenado a pena aflictiva se encuentra en tensión con el primero de los criterios, pues desde el punto de vista democrático es complejo hablar de un sujeto moralmente relevante en el caso de la pérdida del derecho a participar en la configuración política de la comunidad.

Por otra parte, una pena que se "endurezca" para evitar la comisión de nuevos delitos dejaría de lado el segundo de los argumentos expresados. El perdón y sobre todo la reconciliación son cuestiones por defecto posibles en una pena que se ejecuta y configura correctamente, y que además no debería horadar la proporcionalidad.

Luego, si la pena se ejecuta en condiciones indecentes, como es el caso de muchos penales en nuestro país, entonces no estamos dando espacio al tercer argumento, no hay relevancia de la postura moral del sujeto como se tiene en la penitencia, ni se presta atención al posible acto reconciliatorio. Una pena ejecutada en condiciones indecentes no permite exigir al sujeto nada.

Sin embargo, es posible encontrar una gran zona gris en este argumento.

La cuestión difícil está en la explicación de la racionalidad interna de la privación de libertad. Como hemos visto, el esquema parece sugerente teniendo a la vista la afirmación de la mecánica de las penas alternativas a la privación de libertad (con el ejemplo del trabajo en beneficio de la comunidad) y a la negación de castigos especialmente intensos en la puesta a prueba de la racionalidad, como es la pena de muerte.

La privación de libertad merece una atención especial. ¿En qué medida puede explicarse el uso de la prisión como una herramienta de reconciliación?

Evidentemente, la respuesta requiere considerar que el esquema señalado por Duff se mueve en el ámbito de las precomprensiones, y en ese sentido puede que no genere una explicación detallada. ${ }^{30}$

${ }^{30}$ Un contrapunto interesante es el otorgado por Dagger en lo que denomina la tesis del "juego limpio" (fair play). Siguiendo una interpretación que considere el espacio de conducta para los ciudadanos bajo un 
Por ahora, puede decirse que la privación de libertad se encuentra dentro de los límites de la proporcionalidad del sistema, que su estructura, esto es, su forma, no debe ser tenida como un obstáculo a la reconciliación.

Tal como el trabajo en beneficio de la comunidad debe ser enfocado desde la seriedad de la prestación (esto es, sin considerarlo una reparación material solamente), la privación de libertad debe ser compatibilizada con una clase de padecimiento moral que puede ser alineado con el argumento aquí presente. Esto implica tener siempre dudas acerca de la funcionalidad del espacio de tiempo dedicado al encierro, sin dejar de lado la seriedad del castigo (sin pretender trivializar la pena) y, sobre todo, sin traspasar la proporcionalidad.

\section{BIBLIOGRAFÍA}

Dagger, R. (2008). “Punishment as fair play”, en Res Publica, núm. 14, pp. 259-275.

Duff, R. A. (2000). Punishment, communication, and community. New York: Oxford University Press.

Duff, R. A. (2003). Penance, Punishment and the limits of community, en Punishment and Society, núm. 5, pp. 295-312.

Duff, R. A. (2005). Notes on Punishment and Terrorism, en American Behavioral Scientist, núm. 48, pp. 758-763.

Duff, R. A. (2007). Answering for crime. Responsibility and Liability in the Criminal Law, Oxford and Portland: Hart Publishing.

Finkelstein, C. (2004). "Comments on Antony Duff's Penance, Punishment, and the Limits of community", en Punishment and Society, núm. 9, pp. 99-104.

Hampton, J. (1995). The moral education theory of punishment, en Simmons, A.; Cohen, M.; Cohen, J.; Beitz, C., "Punishment", Princeton: Princeton University Press, pp. 112-142.

KulemkampfF, A. (1989). "Ética nomológica y moral de los sentimientos. Observaciones sobre un problema descuidado por la filosofía práctica”, en Doxa, núm. 6, pp. 405-425.

Mañalich, J. P. (2007). La pena como retribución. En Revista de Estudios Públicos, núm. 108, pp. 117-205.

Moore, M. (1998). Placing Blame. A General Theory of Criminal Law, Oxford: Clarendon Press.

Murphy, J. (2003). Christianity and Criminal Punishment, en Punishment and Society, núm. 5, pp. 261-277.

Roxin, C. (1997). Derecho Penal. Parte General. Fundamentos. La estructura de la teoría del delito. Madrid: Civitas.

Tunick, M. (1992). Punishment: Theory and Practice. Berkeley: University of California Press.

esquema de raíces liberales, Dagger entiende que el derecho y el derecho penal implican considerar la idea de obligación política, en particular considerar que el derecho penal se constituye por medio de la obligación general de obedecer la ley. La tesis de Dagger descansa en una concepción de justicia liberal, heredera de la idea de deberes públicos presente en Hart y Rawls. Probablemente, este dato, la raíz liberal, no entregue demasiada información por sí sola, pero recordemos que la tesis de Duff puede ser vista como una tesis no liberal. Una cuestión interesante está en verificar que la gran ventaja que, como hemos anotado, otorga Duff a la comprensión liberal es la autonomía privada. Como vemos, la tesis de Dagger golpea con fuerza en esa comprensión de Duff. La raíz liberal le sirve de base para hablar de deberes públicos, es decir, de vinculaciones del ciudadano con el derecho que no responden tan sólo a la idea de protección de la autonomía privada. 
Turner, J. (2007). “Justice and Emotions”, en Soc Just Res, núm. 20, pp. 288-311.

Valenzuela, J. (2005). "El estado actual a la reforma del sistema penitenciario en Chile", en Revista de Estudios de la Justicia, núm. 6, pp. 191-209.

Valenzuela, J. (2009). La pena y la educación. Una aproximación al fundamento de la pena juvenil. En Revista de Estudios de la Justicia, núm. 11, pp. 235-261.

Von Hirsch, A. (1998). Censurar y castigar, Barcelona: Trotta (traducción de Elena Larrauri). 